\title{
Digamos ¡NO!
}

\author{
No, jo dic no, diguem no. \\ Raimon Pelegero
}

\section{Sr. Editor:}

La actual coyuntura económica está generando una suerte de sensación de fatalismo, que hace a muchos permanecer impasibles ante la pérdida de grandes logros de nuestra sociedad que costó años conseguir. Es más, nuestros gobernantes han sabido fomentar un sentimiento de culpa, a la que se es tan propenso en nuestra tradición judeocristiana, por haber estado viviendo por encima de nuestras posibilidades.

Pero difícilmente van a hacernos sentir así en atención primaria. La bonanza económica pasó de largo para nosotros. Políticas populistas centraron el interés del desarrollo del Sistema Nacional de Salud en la expansión hospitalaria, abandonando a su suerte a la atención primaria. Mientras se creaban hospitales por doquier y se hipertrofiaban servicios, a veces sólo para dar salida laboral a los residentes que iban terminando, cuando no con el objetivo de satisfacer ambiciones personales de jefes de servicio ávidos de mayor peso específico en sus organizaciones, los médicos de familia que terminan su residencia se encuentran abocados, en muchas ocasiones a trabajar un día aquí otro allí, frecuentemente con contratos que no abarcan toda la semana. Para mayor inquina, han de esperar "las migajas" de lo que queda después de que médicos (?) sin formación específica de postgrado (extracomunitarios, con la intención de burlar la legalidad) les dejen.

Esto no es una cuestión política, no podemos quedarnos al margen de unas decisiones que se pretende avalar con el peso de los votos. Muy al contrario, hay argumentos científicos de peso que debemos esgrimir para subrayar la eficiencia de los servicios prestados en atención primaria, frente al "saco sin fondo" de los hospitales. Y es responsabilidad de las sociedades científicas y de las publicaciones profesionales clarificar estos puntos de vista, algo habitual en los países de nuestro entorno.

El British Medical Journal se ha hecho eco de estas preocupaciones. Para Fiona Godlee ${ }^{1}$, editora de la revista, hay que hablar de "intervenciones y servicios que habría que dejar de ofrecer para REV CLÍN MED FAM 2012; 5 (1): 76-78 ahorrar dinero y mejorar la asistencia". Así plantea, siguiendo recomendaciones de diversos expertos, reconsiderar las endoscopias en personas con mínimos sangrados gastrointestinales, la revascularización en personas con angina estable antes de que hayan recibido un tratamiento farmacológico óptimo, la resección de metástasis pulmonares en el cáncer colorrectal avanzado, la solicitud de tests de laboratorio de rutina, el uso de combinaciones de corticoides y antibióticos tópicos en eccemas, las cesáreas sin indicación médica, los programas para mejorar el acceso a servicios psicológicos, las radiografías en el dolor lumbar o los corticoides inhalados para la enfermedad pulmonar obstructiva crónica leve o moderada. Así mismo sugiere fomentar tratamientos alternativos más baratos, como la fototerapia para pacientes con psoriasis moderada a severa, en lugar de los más costosos tratamientos biológicos. Junto a esto, hace hincapié en la necesidad de disponer de servicios comunitarios fuertes, que permitan la asistencia de los pacientes fuera de los hospitales.

Otra prestigiosa revista, el European Journal of General Practice, señalaba en un reciente editorial la necesidad de invertir en atención primaria para conseguir una atención sanitaria más eficiente ${ }^{2}$.

Es cierto que alguna iniciativa se ha visto por parte de las sociedades científicas. Así, el Foro de Médicos de Atención Primaria ${ }^{3}$, en su reunión del 19 de enero mostraba su convencimiento de "que la mejora de la Atención Primaria es imprescindible para la sostenibilidad del sistema sanitario $y$, además, ahorradora de recursos". Es un buen comienzo, pero hay que ser más ambicioso en la denuncia de las políticas actuales.

No podemos adormecernos con "cantos de sirena" que nos hablan de que somos privilegiados, y que tenemos que asumir la parte de sacrificio que nos corresponde. Nada hemos tenido que ver en el origen de esta situación, y en absoluto se puede llamar privilegiado a quien ha tenido que pasar por un largo proceso formativo y selectivo para realizar un trabajo de alta responsabilidad y mal pagado con relación a los médicos de otros países de nuestro en torno. Hay que decir bien alto que es inadmisible que además se baje el sueldo y se aumenten horas 
de trabajo, o que suframos demoras en el pago de nuestros salarios. ¿Cómo puede consentirse que estén sin pagar actividades de docencia desde 2010? ¿Por qué aguantamos que la productividad de 2011 no se cobrara después de recibir la nómina correspondiente?... ¿Cómo admitimos que el trabajo de profesionales altamente cualificados esté en manos de estos gestores? Porque, efectivamente, estamos en manos de unos gestores nombrados con un criterio político, en base a la adscripción partidista, poco importa su conocimiento de aquello que tienen que gestionar.

La cualificación requerida y la alta responsabilidad de nuestro trabajo deben determinar un rechazo a medidas arbitrarias. No debemos admitir las políticas de recorte, reduciendo presupuestos a "tajo parejo", sin parase a discriminar cómo sacar mayor rendimiento a los recursos. Así, nos vemos en la misma situación los servicios infradotados y los hipertrofiados; o nos encontramos con medidas como la paralización del proceso de carrera profesional que castiga a quienes están en espera de reconocimiento de méritos frente a quienes tuvieron la suerte de llegar antes.

Por mucho que nieguen un interés en liquidar el Sistema Nacional de Salud, difícilmente nos van a convencer mientras sigan por este camino.

\section{BIBLIOGRAFÍA}

1. Fiona Godlee. Room 101, where services go to die. BMJ. 2010; 340:c1523.

2. Henk van Weert. The economic crisis is the right moment to invest in primary care. Eur J Gen Pract. 2011; 17:203-4.

3. Conclusiones del Foro de Médicos de Atención Primaria. http://www.noticiasmedicas.es/medicina/noticias/12790/1/ Conclusiones-del-Foro-de-Medicos-de-Atencion-Primaria/ Page1.html (con acceso el 31-1-2012).

\section{Francisco Escobar Rabadán} Médico de Familia Centro de Salud Zona IV de Albacete

\section{CAMBIO DE DIRECCIÓN}

Le rogamos nos avise con antelación en caso de cambio de dirección para no alterar el servicio de recepción de REVISTA CLÍNICA DE MEDICINA DE FAMILIA.

Los cambios deben comunicarse en el teléfono 967507911 o a través del correo electrónico info@scamfyc.org

\section{SUSCRIPCIONES Y ATENCIÓN AL CLIENTE}

\section{SCAMFYC}

Dionisio Guardiola, $16,4^{\circ} \mathrm{D}$

02003- Albacete

Teléfono y Fax: 967507911

Correo electrónico: info@scamfyc.org

Tarifa de suscripción anual

Profesionales 40,00 Euros (IVA incluido)

Instituciones 120,00 Euros (IVA incluido) 